\title{
Phenetic Characterization of Plum Cultivars by High Multiplex Ratio Markers: Amplified Fragment Length Polymorphisms and Inter-simple Sequence Repeats
}

\author{
Luís Goulão, ${ }^{1}$ Luisa Monte-Corvo, ${ }^{1}$ and Cristina M. Oliveira ${ }^{2}$ \\ Instituto Superior de Agronomia, Universidade Técnica de Lisboa, Secção de Horticultura, Tapada da \\ Ajuda 1349-017, Lisboa, Portugal
}

AdDitional INDEX wORDs. cultivar identification, phenetic similarities, marker comparison, molecular markers

\begin{abstract}
Variability of commercial plum (Prunus L. sp.) cultivars is unknown since breeding often involves intercrossing hybrids with several species but has been based on a low number of parents. Molecular markers like amplified fragment length polymorphisms (AFLP) and inter-simple sequence repeats (ISSR), which sample multiple loci simultaneously, have become increasingly popular, and were used to characterize 24 diploid and four hexaploid cultivars of plum. Seven AFLP and six ISSR primers were used, and resulted in amplification of 379 and 270 products, respectively. Unweighted pair-group method with arithmetic averages (UPGMA) dendrograms, based on similarity coefficients, reflected a clear separation between diploid and hexaploid plums. Among diploid plums, two pairs of cultivars were relatively distinct from the rest, namely 'Golden Japan' and 'Methley' and 'Ozark Premier' and 'Songold'. Furthermore, several cultivars were grouped together both with AFLP and ISSR analysis: 1) 'Ambra', 'Red Beaut', and 'Black Beaut', 2) 'Black Diamond' and 'Royal Diamond', 3) 'June Rose', 'Santa Rosa', and 'Royal Red', and iv) 'Freedom', 'Larry Ann', and 'Queen Rosa'. Although the phenetic classification obtained by the two methods were similar $(r=0.73$, for the diploid group), ISSR had a higher reproducibility and percentage of polymorphisms $(87.4 \%$ vs. $62.8 \%)$ than AFLP. Methodological aspects of both markers systems are discussed. Results obtained suggest that the AFLP and ISSR approaches are valuable tools for identification of specific genotypes and analysis of phenetic relationships in plum.
\end{abstract}

Plums are unusual in being domesticated independently on three different continents-Europe, Asia, and North America. Most plums in commercial production today are classified as European (hexaploid; $2 n=48$ ) or Japanese (diploid; $2 n=16$ ) types (Okie and Weinberger, 1996). The term Japanese plum was applied originally to Prunus salicina Lindl. but the majority of new releases involve intercrossing hybrids with several other plum species, including $P$. americana Marsh., P. munsoniana Wight. and Hedr., P. simonii Carr., and P. cerasifera Hedr. However, the variability among cultivars is still unknown since breeding in recent years has been based on a low number of parents. Byrne and Littleton (1988) refer to high levels of isozyme polymorphism among a set of diploid plums but, according to Howard (1945), interspecific hybrids can be closely related since only a limited number of parents were used from $P$. salicina and P. americana.

Availability of wide genetic diversity is of primary importance in plant breeding, since a representative reserve of alleles and genotypes may become useful for responding to future changes. Knowledge of the diversity available helps determine the best crosses to make for increasing diversity or for transferring a reduced number of characteristics among cultivars. Moreover, since tree fruit cultivars are maintained by vegetative propagation, accurate identification of vegetative material is crucial for nurserymen and growers, and is needed for plant breeder's rights.

Received for publication 24 Feb. 2000. Accepted for publication 3 May 2000. We gratefully acknowledge Kenneth Tobutt (Horticulture Research International, East Malling, United Kingdom) for valuable suggestions and critical review of the manuscript. This work was supported financially by Fundação para a Ciência e Tecnologia (FCT), project PRAXIS 2143, Lisbon, Portugal. The cost of publishing this paper was defrayed in part by the payment of page charges. Under postal regulations, this paper therefore must be hereby marked advertisement solely to indicate this fact.

${ }^{1}$ Graduate student.

${ }^{2}$ Associate professor and corresponding author; e-mail: crismoniz@isa.utl.pt.
Traditional characterization based on morphological, physiological, and agronomic traits has distinct disadvantages since it is regulated developmentally or influenced by genotype $\times$ environment interactions, and by agricultural practices like rootstocks or pruning. In tree fruits, one should also consider the limitations associated with characterization of new hybrids, as a consequence of their long juvenile period. For assessing diversity, it should be remembered that the genes associated with morphological and agronomic traits are limited and do not cover the entire genome.

Molecular markers have been used for cultivar identification and quantification of genetic and phenetic diversity to overcome some of the above mentioned limitations. In management of gene banks, molecular markers can be used to identify duplicates or to select a percentage of the total collection containing most of the genetic diversity to create core collections.

Choice of the marker system to use for a particular application depends on its ease of use and the particular objectives of the investigation (Rafalski et al., 1996). In fruit crops, several reports have compared different molecular markers, as in, citrus (Citrus L.) (Fang et al., 1997), grape (Vitis L.) (Sensi et al., 1996), peach [Prunus persica (L.) Batsch (peach group)] (Dirlewanger et al., 1998), currant (Ribes L.) (Lanham and Brennan, 1999), and pear (Pyrus L.) (Monte-Corvo et al., 2000).

Biochemical and molecular characterization of European and Japanese plums have been reported using isozymes (Byrne and Littleton, 1988) and random amplified polymorphic DNA (RAPD) analysis (Bellini et al., 1998; Gregor et al., 1994; Oritz et al., 1997; Shimada et al., 1999). These markers provide advantages over morphological observations, but still suffer from important problems of reproducibility and insufficient quantity of information per analyses.

More recently, markers like amplified fragment length polymorphism (AFLP) and inter-simple sequence repeats (ISSR), which sample multiple loci simultaneously have become increas- 
ingly important. AFLP combines restriction digestion with polymerase chain reaction (PCR), (Rafalski et al., 1996; Vos et al., 1995) and results in highly informative fingerprints, due to a very high multiplex ratio. A genomic DNA sample is first digested with one rare and one frequent restriction enzyme, and the resulting fragments are amplified using primers complementary to ligated adapters. Arbitrary selective nucleotides at the 3' end of the primers reduce the number of amplified fragments and make them resolvable in a standard sequencing gel. Polymorphisms are obtained with different restriction enzymes and selective nucleotides of the primers employed. ISSR (Zietkiewicz et al., 1994) relies on the ubiquity of microsatellites in eukaryotic genomes. A single primer composed of a microsatellite sequence anchored at the 3' or 5' end by two to four arbitrary, often degenerate nucleotides, is used to amplify the DNA between two opposed microsatellites of the same type. Polymorphisms occur whenever one genome lacks the repeated sequence or has a deletion or insertion that modifies the distance between repeats. For 5' anchored primers, polymorphisms also occur due to differences in the length of the microsatellite. The sequences of repeats and anchored nucleotides are selected randomly. In the present paper, we compare the potential of AFLP and ISSR markers for fingerprinting a set of commercial plum cultivars and estimating phenetic similarities.

\section{Materials and Methods}

Plant material. A total of 28 commercial plum cultivars were selected for this study (Table 1). The twenty-four diploid plum cultivars ( $P$. salicina and hybrids) used compose a field collection maintained in 'Estação Nacional de Fruticultura Vieira Natividade', Alcobaça, Portugal. The four hexaploid plum cultivars $(P . \times$ domestica) were collected from 'Núcleo de Ensaios de Controlo do Escaroupim', Salvaterra de Magos, Portugal and were used as an outgroup to diploid plums.

DNa ISOLATION. DNA was extracted from fresh, young leaf tissue, by a cetyltrimethylammonium bromide (CTAB) based method adapted from Doyle and Dolyle (1990), as described previously (Oliveira et al., 1999). The extract was further purified by a RNase A treatment and phenol : chloroform : isoamyl alcohol (25:24:1) extractions, using standard methods (Sambrook et al., 1989). Concentration and purity of the DNA extracted was determined by electrophoresis in $1 \%$ agarose gels and spectrophotometrically. This extraction method yielded an average DNA content of $477.6 \mu \mathrm{g} \cdot \mathrm{g}^{-1}$ of leaf tissue, and purified DNA revealed $\mathrm{A}_{260} / \mathrm{A}_{280}=1.83 \pm 0.33$ when assessed spectrophotometrically, revealing samples free of contaminants. The same DNA was used for both AFLP and ISSR analysis.

AFLP ASSAYs. All reagents required for AFLP analysis were obtained from Life Technologies Inc. (Paisley, United Kingdom), as kits, except for Taq DNA polymerase (Amersham Pharmacia Biotech, Uppsala, Sweden), and manufacturer's procedures were followed with minor modifications up to selective amplification, since a nonradioactivity method was used to detect the amplified fragments. Selective amplification reactions were carried out in volumes of $20 \mu \mathrm{l}$, containing $5 \mu \mathrm{l}$ of preamplification

Table 1. List and background information of the 28 plum cultivars characterized (Brooks and Olmo, 1997).

\begin{tabular}{|c|c|c|c|}
\hline Code & Cultivar & & Reported parentage \\
\hline & & \multicolumn{2}{|l|}{ Diploid cultivars } \\
\hline 1 & Songold & & 'Goldenking' x ‘Wickson' \\
\hline 2 & Santa Rosa & & Unknown \\
\hline 3 & Royal Red & & Open pollination of 'Red Beaut' \\
\hline 4 & Royal Diamond & & Unknown \\
\hline 5 & Red Beaut & & 'Eldorado’ x ‘Burmosa' \\
\hline 6 & Queen Rosa & & 'Queen Ann' x 'Santa Rosa' \\
\hline 7 & Ozark Premier & & 'Burbank' x 'Methley' \\
\hline 8 & Methley & & Unknown $(P$. salicina $\times P$. cerasifera $)$ \\
\hline 9 & Larry Ann & & Unknown \\
\hline 10 & Laroda & & 'Gaviota' x 'Santa Rosa' \\
\hline 11 & June Rose & & Unknown \\
\hline 12 & Friar & & 'Gaviota' x 'Nubiana' \\
\hline 13 & Freedom & & Unknown \\
\hline 14 & Fortune & & 'Laroda' x ('Queen Ann' x 'Late Santa Rosa') \\
\hline 15 & Eldorado & & Unknown \\
\hline 16 & Durado & & 7a-31M x 'Burmosa' \\
\hline 17 & Black Star & & Chance seedling \\
\hline 18 & Black Gold & & Sport from 'Ace' \\
\hline 19 & Black Diamond & & ‘Angeleno’ x 'Midsummer' \\
\hline 20 & Black Beaut & & Open pollination of 'Red Beaut' \\
\hline 21 & Black Amber & & 'Friar' x 'Queen Rosa' \\
\hline 22 & Angeleno & & Open pollination of 'Queen Ann' \\
\hline 23 & Ambra & & Unknown \\
\hline \multirow[t]{2}{*}{24} & Golden Japan & & Unknown (? open pollination of 'Wickson') \\
\hline & & Hexaploid cultivars & \\
\hline 25 & Stanley & & 'Agen' x 'Grand Duke' \\
\hline 26 & Reine Claude Violet & & Unknown \\
\hline 27 & Reine Claude Vert & & Unknown \\
\hline 28 & President & & Unknown \\
\hline
\end{tabular}


Table 2. Sequences of AFLP primers and adapters and ISSR primers used in PCR amplifications.

\begin{tabular}{|c|c|}
\hline AFLP primer/adapter & Sequence $\left(5^{\prime}-3^{\prime}\right)$ \\
\hline \multirow[t]{2}{*}{ EcoRI adapter } & 5'-CTCGTAGACTGCGTACC \\
\hline & CATCTGACGCATGGTTAA-5, \\
\hline \multirow[t]{2}{*}{ MseI adapter } & 5'-GACGATGAGTCCTGAG \\
\hline & TACTCAGGACTCAT-5, \\
\hline EcoRI core primer & GACTGCGTACCAATT \\
\hline MseI core primer & GATGAGTCCTGAGTAAC \\
\hline \multicolumn{2}{|c|}{ Primer combination (EcoRI+3/MseI+3)M-CTA/E-ACA } \\
\hline & M-CAG/E-AAG \\
\hline & M-CTA/E-AAG \\
\hline & M-CTT/E-ACT \\
\hline & M-CAT/E-ACA \\
\hline & M-CAT/E-ACT \\
\hline & M-CTA/E-ACT \\
\hline \multirow[t]{7}{*}{ ISSR primer } & Sequence $\left(5^{\prime}-3^{\prime}\right)$ \\
\hline & $(\mathrm{GA})_{8} \mathrm{YG}$ \\
\hline & $(\mathrm{AG})_{8}^{\circ} \mathrm{YT}$ \\
\hline & $\mathrm{HVH}(\mathrm{GT})_{7}$ \\
\hline & $\mathrm{VHV}(\mathrm{TG})_{7}^{\prime}$ \\
\hline & $\mathrm{HVH}(\mathrm{CA})_{7}$ \\
\hline & $\mathrm{DBD}(\mathrm{AC})_{7}$ \\
\hline
\end{tabular}

template PCR products, $30 \mathrm{ng}$ of EcoRI+3 primer, $30 \mathrm{ng}$ of $M s e I+3$ primer (includes dNTPs), and 1 unit of Taq DNA polymerase (Amersham Pharmacia Biotech) in $1 \times$ reaction buffer $(50$ $\mathrm{mm} \mathrm{KCl}, 1.5 \mathrm{~mm} \mathrm{MgCl}_{2}$, and $10 \mathrm{~mm}$ Tris $\mathrm{HCl}, \mathrm{pH}$ 9.0). AFLP temperature profile, generated by means of a touch-down PCR, was one cycle of $94^{\circ} \mathrm{C}$ denaturation for $30 \mathrm{~s}, 65^{\circ} \mathrm{C}$ annealing for $30 \mathrm{~s}$, and $72^{\circ} \mathrm{C}$ extension for $60 \mathrm{~s}$, followed by 12 cycles with the annealing temperature lowered by $0.7^{\circ} \mathrm{C}$ per cycle. Another 23 cycles were performed at $94^{\circ} \mathrm{C}$ for $30 \mathrm{~s}, 58^{\circ} \mathrm{C}$ for $30 \mathrm{~s}$ and $72^{\circ} \mathrm{C}$ for $60 \mathrm{~s}$. Seven primer combinations were used for selective amplifications. The sequences of adapters and primers used are listed in Table 2.

ISSR ASSAYS. Amplification reactions were carried out in volumes of $20 \mu \mathrm{L}$ containing $30 \mathrm{ng}$ template DNA, 1 unit of Taq DNA polymerase (Amersham Pharmacia Biotech), 0.25 mm each dNTP (Gibco BRL, Paisley, United Kingdom), and $1 \mu \mathrm{M}$ primer (Gibco BRL), in $1 \times$ reaction buffer $(50 \mathrm{~mm} \mathrm{KCl}, 1.5 \mathrm{~mm} \mathrm{MgCl}$, $10 \mathrm{~mm}$ Tris $\mathrm{HCl}, \mathrm{pH}$ 9.0). PCR reactions were performed in a Biometra UNOII (Biometra, Göttingen, Germany) thermal cycler under the following conditions: 4 min at $94{ }^{\circ} \mathrm{C}$ for initial denaturation, 27 cycles of $30 \mathrm{~s}$ at $94^{\circ} \mathrm{C}$ (denaturation), $45 \mathrm{~s}$ at 52 ${ }^{\circ} \mathrm{C}$ (annealing) and $120 \mathrm{~s}$ at $72{ }^{\circ} \mathrm{C}$ (extension), followed by $7 \mathrm{~min}$ at $72^{\circ} \mathrm{C}$ for final extension of the single strands. Thirteen random primers were screened using a bulked DNA sample and six primers were selected for final amplifications (Table 2).

Primer Selection. For both AFLP and ISSR analysis, the number of primers used was that necessary to obtain up to 200 polymorphic markers among diploid plums. In order to select ISSR primers, 13 random primers were screened. Selected primers are listed in Table 2. Primers $(\mathrm{AG})_{8} \mathrm{YT},(\mathrm{GA})_{8} \mathrm{YC},(\mathrm{AT})_{8} \mathrm{YC}$, $(\mathrm{GT})_{8} \mathrm{YC},(\mathrm{CA})_{8} \mathrm{R},(\mathrm{AGC})_{4} \mathrm{YR}$, and (TCC) $)_{5} \mathrm{RY}$ revealed insufficient amplifications in agarose gels and were not used.

GeL ANALYSIS. Both AFLP and ISSR amplified fragments were mixed with an equal volume of formamide dye $(98 \%$ formamide, $10 \mathrm{~mm}$ EDTA, $0.05 \%$ bromophenol blue, and $0.05 \%$ xylene cyanol), loaded onto prewarmed $6 \%$ polyacrylamide gels, and separated electrophoretically in $1 \times \mathrm{TBE}$ buffer, at $50 \mathrm{~W}$ constant power until the dye had advanced on $2 / 3$ of the gel. While ISSR fragments were resolved under $3 \mathrm{~m}$ urea nondenaturing conditions, AFLP bands were separated in $7.5 \mathrm{~m}$ urea denaturing conditions; the samples were denatured at $94{ }^{\circ} \mathrm{C}$ for $3 \mathrm{~min}$ and cooled immediately in ice before loading the gel. Both AFLP and ISSR gels were silver stained as described in Bassam et al. (1991).

REPRODUCIBILITY TESTS. For both methods, reproducibility tests were done. Duplicate DNA extractions were used and PCR reactions were performed in different days by two different operators.

Data ANALYSIS. The information content of each marker system was determined according to the indices of Powell et al. (1996): effective multiplex ratio (number of polymorphic products from a single amplification reaction), expected heterozygosity $\left(H=1-\Sigma p_{i}^{2}\right.$, where $p_{i}$ is the allele frequency for the $i^{\text {th }}$ allele $)$ and marker index (the product of effective multiplex ratio and expected heterozygosity). These calculations were performed using only the diploid cultivar group.

Similarity values were estimated based on the fraction of bands common to each pair of cultivars, according to Nei and Li's (1979) coefficient: $S_{i j}=2 N_{i j} /\left(N_{i}+N_{j}\right)$, where $N_{i j}$ is the number of bands shared between cultivars $i$ and $j$, and $N_{i}$ and $N_{j}$ are the number of bands for cultivars i and $\mathrm{j}$, respectively.

Cluster analysis was performed to construct dendrograms, using the unweighted pair-group method with arithmetic averages (UPGMA) from the similarity data matrices. The Numerical Taxonomy and Multivariate Analysis System program package for personal computer (NTSYS-pc version 1.8; Rohlf, 1993) was used for statistical analysis of data.

\section{Results}

With AFLP analysis, seven primer combinations produced 204 polymorphic markers, while with ISSR analysis, six primers produced 208 polymorphic markers. In total, 379 AFLP products were obtained from amplification of the 28 cultivars, of which 279 were polymorphic $(73.6 \%)$. The scorable amplified fragment sizes ranged from 100 to 500 base pairs (bp). An example of the patterns obtained is illustrated in Fig. 1.

Of the 270 ISSR bands observed, 259 were polymorphic, accounting for a high percentage $(95.9 \%)$ of polymorphisms. Fragments in the scored area of the gels ranged from 100 to 2000 $\mathrm{bp}$, but larger fragments existed in a very high number. However, the great proximity between these markers in the gels made them very difficult to score without errors (Fig. 2).

To compare the utility of the two marker systems, the diploid cultivar group was used (Table 3). Use of both diploid and hexaploid plums would overweigh the poymorphism values due to the multispecies nature of cultivated plums. In the AFLP analysis, each primer combination produced 26 to 65 bands, with an average of 46.4. A total of 325 bands were scored. For ISSR analysis, the average number of bands observed per primer was 39.7 with a range from 33 to 48 , for a total of 238 bands. The ISSR marker index 11.7 (indicative of marker utility) was superior to AFLPs, which is 9.5, due to ISSR's higher effective multiplex ratio, since similar results were observed for expected heterozygosity. In fact, the effective multiplex ratio was 17 for ISSR analysis, while for AFLP, only 14 polymorphic bands were scored per single reaction, despite the higher multiplex ratio of AFLP. The higher percentage of polymorphic bands obtained from ISSR analysis (87.4\% compared to $62.8 \%$ for AFLPs) 
suggests that ISSR markers are able to detect more polymorphisms among plum cultivars, than are AFLP markers. The phenetic similarity obtained between diploid cultivars revealed an average of 0.84 and 0.71 for AFLP and ISSR, respectively. ISSR markers provided a clearer separation of the cultivars.

Similar results were seen among the small sample of hexaploid plums. Two hundred and fifty eight AFLP products were amplified, of which $80(31 \%)$ were polymorphic. Using the ISSR methodology, 200 bands were observed and $67.5 \%$ were polymorphic. Although not comparable with the results obtained for the diploid plums group due to the small sample number, these results may indicate less diversity among the hexaploid group compared with the diploid group. Again, the ISSR assay detected more polymor-

$122 \quad 3 \quad 4 \quad 5 \quad 6 \quad 7 \quad 891011121314151617181920212223242526272829$

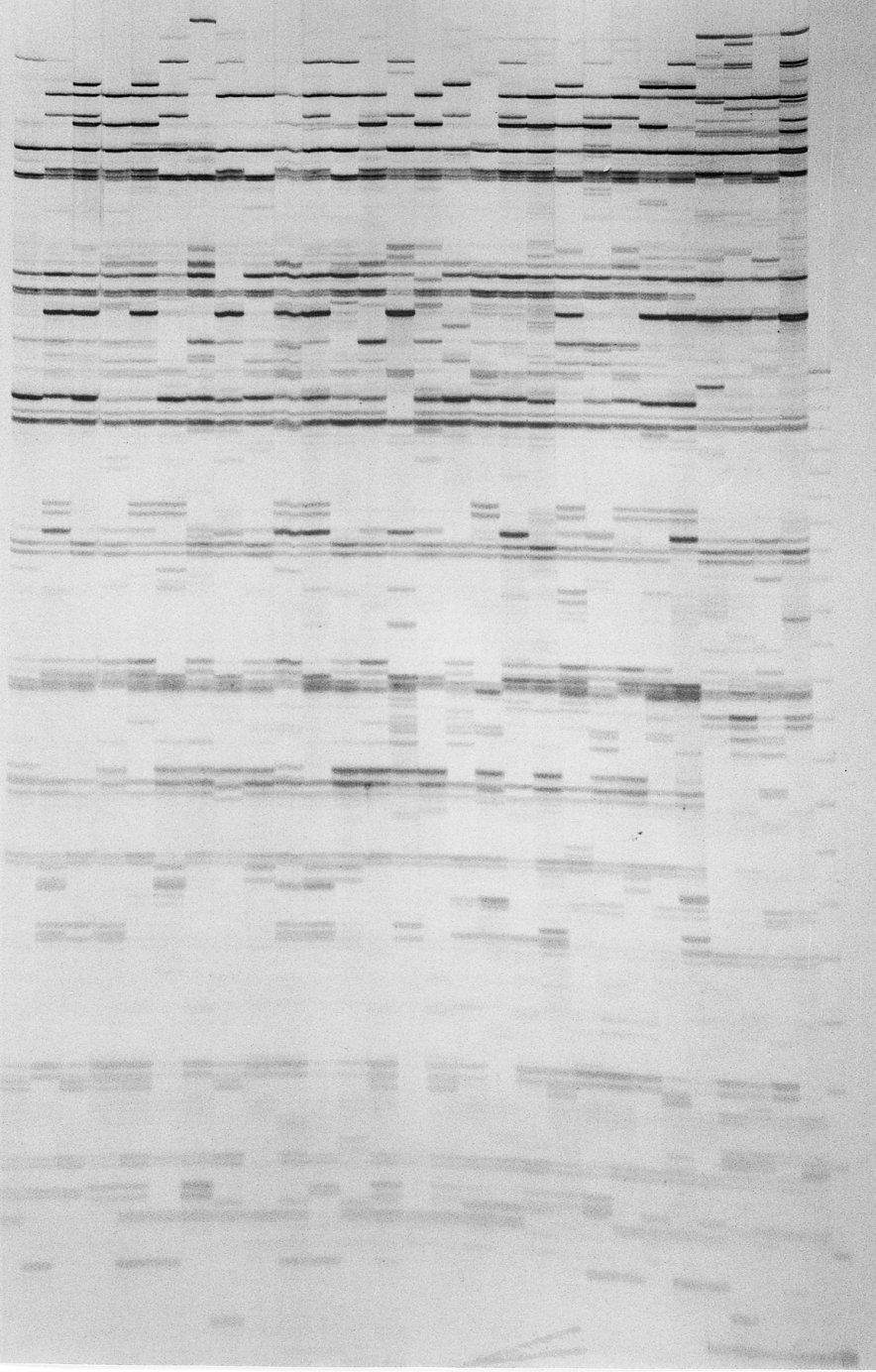

Fig. 1. AFLP amplification profile generated from the 28 plum cultivars using primer combination M-CTT/E-ACT. From left to right, lane 1, 'Songold'; lane 2, 'Santa Rosa'; lane 3, 'Royal Red'; lane 4, 'Royal Diamond'; lane 5, 'Red Beaut'; lane 6, 'Queen Rosa'; lane 7, 'Ozark Premier'; lane 8, 'Methley'; lane 9, 'Larry Ann'; lane 10, 'Laroda'; lane 11, 'June Rose'; lane 12, 'Friar'; lane 13, 'Freedom'; lane 14, 'Fortune'; lane 15, 'Eldorado'; lane 16, 'Durado'; lane 17, 'Black Star'; lane 18, 'Black Gold'; lane 19, 'Black Diamond'; lane 20, 'Black Beaut'; lane 21, 'Black Amber'; lane 22, 'Angeleno'; lane 23, 'Ambra'; lane 24, 'Golden Japan'; lane 25, 'Stanley'; lane 26, 'Reine Claude Violet'; lane 27, 'Reine Claude Vert'; lane 28, 'President'; lane 29, molecular weight marker 30330 bp ladder (Gibco, BRL). phic bands than the AFLP methodology. ISSR analysis was perfectly reproducible whereas the AFLP procedure resulted in $1 \%$ to $3 \%$ of the fragments that were not reproducible in the restriction cut step.

AFLP and ISSR cluster analysis is illustrated in the dendrogram of Fig. 3. The cophenetic matrices computed from the tree matrices showed significant correlations of $97.5 \%$ and $97.0 \%$ with the original AFLP and ISSR similarity matrices, respectively, revealing in both cases very good agreement of the dendrograms with the original data. The dendrograms derived from the AFLP and ISSR cluster analysis show a clear separation between diploid and hexaploid plums. Among diploid plums, two pairs of cultivars are relatively distinct from the rest, namely 'Golden Japan' and 'Methley' and 'Ozark Premier' and 'Songold'. The hybrid character of these cultivars can explain this evidence. In fact, the first three cultivars have a very important contribution of $P$. cerasifera in their ancestry.

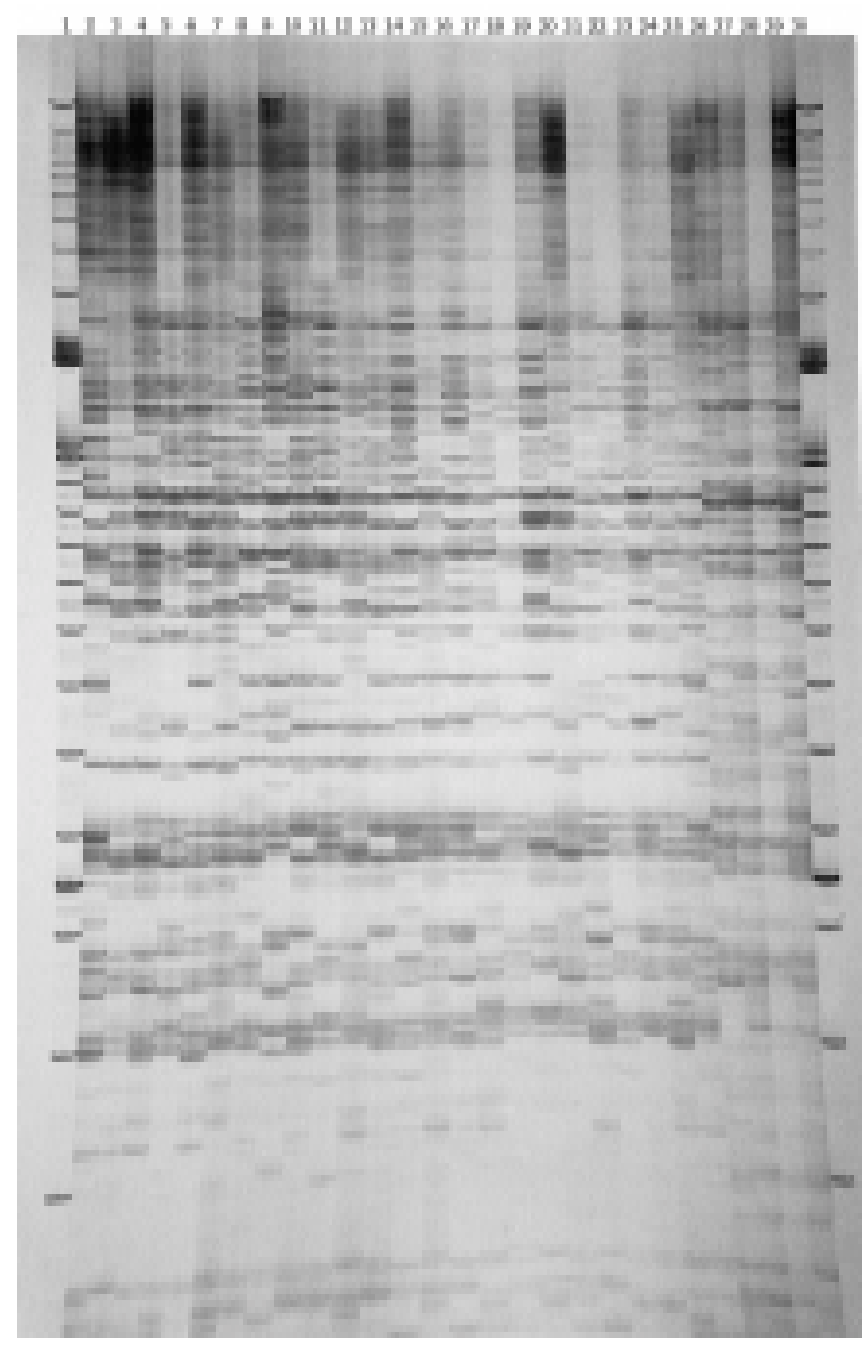

Fig. 2. ISSR amplification profile generated from the 28 plum cultivars using primer $\mathrm{HVH}(\mathrm{TG})_{7}$. From left to right, lane 2, 'Songold'; lane 3, 'Santa Rosa'; lane 4, 'Royal Red'; lane 5, 'Royal Diamond'; lane 6, 'Red Beaut'; lane 7, 'Queen Rosa'; lane 8, 'Ozark Premier'; lane 9, 'Methley'; lane 10, 'Larry Ann'; lane 11, 'Laroda'; lane 12, 'June Rose'; lane 13, 'Friar'; lane 14, 'Freedom'; lane 15, 'Fortune'; lane 16, 'Eldorado'; lane 17, 'Durado'; lane 18, 'Black Star'; lane 19, 'Black Gold'; lane 20, 'Black Diamond'; lane 21, 'Black Beaut'; lane 22, 'Black Amber'; lane 23, 'Angeleno'; lane 24, 'Ambra'; lane 25, 'Golden Japan'; lane 26, 'Stanley'; lane 27, 'Reine Claude Violet'; lane 28, 'Reine Claude Vert'; lane 29, 'President'; lane 1 and 30, molecular weight marker 100 bp ladder (Pharmacia, Biotech). 
Table 3. Analysis of banding patterns generated by AFLP and ISSR assays for the 24 diploid plum cultivars.

\begin{tabular}{lcc}
\hline \hline Banding patterns & AFLP & ISSR \\
\hline Number of scorable bands & 325 & 238 \\
Number of polymorphic bands & $204(62.8 \%)$ & $208(87.4 \%)$ \\
Number of scorable bands per primer $^{\mathrm{z}}$ & $46.4 \pm 13.5$ & $39.7 \pm 5.4$ \\
Multiplex ratio $^{\mathrm{y}}$ & 32 & 22 \\
Effective multiplex ratio $^{\mathrm{y}}$ & 14 & 17 \\
Expected heterozygosity $^{\mathrm{x}}$ & 0.68 & 0.69 \\
Marker index $^{\mathrm{w}}$ & 9.52 & 11.73
\end{tabular}

${ }_{\mathrm{z}}$ Number of products from a single amplification reaction.

${ }^{y}$ Number of polymorphic products from a single amplification reaction.

${ }^{\mathrm{x}} \mathrm{H}=1-\Sigma \mathrm{p}_{\mathrm{i}}^{2}$, where $\mathrm{p}_{\mathrm{i}}$ is the allele frequency for the $\mathrm{i}^{\text {th }}$ allele.

wProduct of Effective Multiplex Ratio and Expected Heterozygosity.

Concerning 'Songold', we postulate that one of its progenitors, 'Golden King', is a hybrid involving $P$. cerasifera, like another important South African cultivar, 'Methley'. Furthermore, several cultivars were grouped together in the two analysis systems: i) 'Ambra', 'Red Beaut', and 'Black Beaut', ii) 'Black Diamond' and 'Royal Diamond', iii) 'June Rose', 'Santa Rosa', and 'Royal Red', and iv) 'Freedom', 'Larry Ann', and 'Queen Rosa'. The correlation between the similarity matrices from AFLP and ISSR data was $73.0 \%$ when only the diploid species were considered and $95.1 \%$ with both plum types (Fig. 3).

\section{Discussion}

Results suggest that both AFLP and ISSR analysis yield similar results and have great potential to identify and establish phenetic relationships among plum cultivars. Both methods are highly informative and do not require prior knowledge of the genome. The ISSR assay showed, however, some advantages over AFLP, as it is more reproducible and more informative. Although ISSR had a lower multiplex ratio, the effective multiplex ratio was superior to that calculated for AFLP. In the ISSR assay, isolated DNA is directly analyzed without the need for further manipulations, making the technique quite easy. Moreover, AFLP has license restrictions limiting its use for commercial fingerprinting.

The markers used in this work appeared superior to RAPD markers. Shimada et al. (1999) reported an average of 14.2 bands per analysis, after an extensive selection of primers. Furthermore, these authors observed a low percentage of polymorphism (24\%).

The AFLP technique has been reported as more reproducible than RAPD methodology (Jones et al., 1997) because longer primers are used, and the annealing occurs at higher melting temperatures. In our work, we have also obtained high reproducibility in the amplification steps, but some irreproducibility was observed from incomplete restriction cuts of the DNA. AFLP profiles from the same DNA sample digested separately (same extraction but different restriction cuts) differ in about $1 \%$ to $3 \%$ of the bands. These results agree with AFLP work in other species (Hartl and Seefelder, 1997; Tohme et al., 1996). Donini et al. (1997) observe different AFLP patterns in different tissues of wheat (Triticum aestivum L.) and suggested this was caused by differential DNA methylation, as they were using a methylation-sensitive restriction enzyme. However, in the present work, the same percentage of irreproducible bands were found using the $N s p \mathrm{~V}$ enzyme, which cuts the DNA independently of any existent methylation (Nelson and McClelland, 1991), suggesting that the problem is not restricted to methylation. Reproducibility problems in AFLP methods can be due to the presence of certain contaminants, such as polysaccharides in the DNA samples. This fact can be a major disadvantage for fingerprinting, but also for other routine AFLP analysis, such as bulk segregant analysis or mapping, in which a large number of samples (entire $F_{1}$ and $F_{2}$ descendants of a particular cross) must be analyzed simultaneously. The need for rigorous, laborious, and expensive purification methods represents a major drawback,

\section{(A) AFLP}
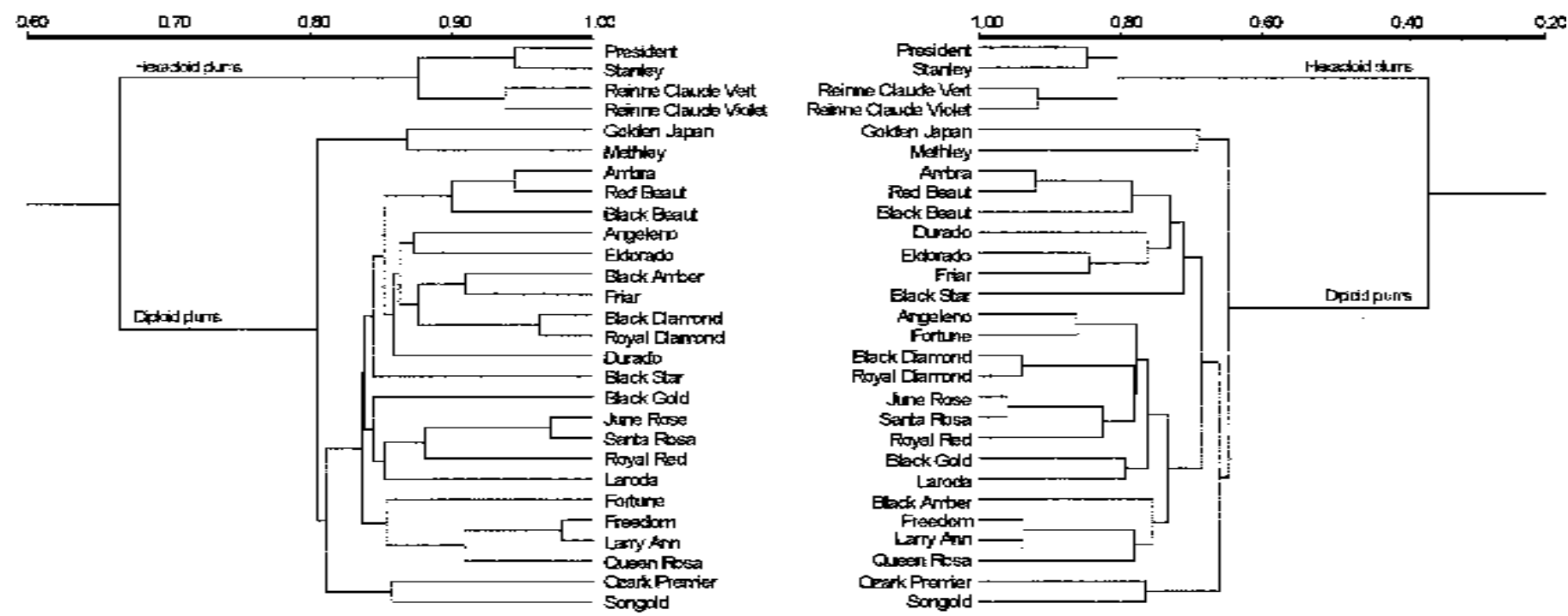

Fig. 3. UPGMA dendrogram of phenetic similarities among the 28 plum cultivars, based on Nei and Li's (1979) coefficient values computed from (A) 379 AFLP products, and (B) 270 ISSR products. The cophenetic correlations are $97.5 \%$ and $97.0 \%$, respectively. 
and fast and readily employed DNA extraction methods, as the one described by Lange et al. (1998), would be advantageous.

In the original AFLP and ISSR procedures, fragments were detected by autoradiography, using radioactive labelling. Silver staining provides, however, a valuable alternative to the use of radioisotopes, as it avoids use of hazardous radioactivity, is fast (about $90 \mathrm{~min}$. after the electrophoresis run), sensitive, and less expensive. Moreover it is comparable to radiolabelling in sensitivity. Silver staining procedures are also an advantage when it is necessary to recover an amplified fragment, since, unlike radioactive methods, the fragment is visible in the gel, making the work less laborious.

The methods employed in this study, although often suitable for cultivar fingerprints, have some aspects that can be disadvantageous for some other purposes. First, as often discussed for RAPDs, same size products on the gels, from different genotypes, do not necessarily have the same sequence. This possibility increases when more remote materials are compared. This aspect limits use of these markers for phylogenetic analysis and determination of genetic distances, although they can be used for estimation of these parameters, by means of phenetic similarities. Another shortcoming is the presence of nonparental novel bands. This aspect may be due to competition in the PCR reaction, which can be a source of genotyping errors (Halldén et al., 1996). The presence of nonparental bands was also found in this work. Thus, 'Black Amber' ('Queen Rosa' x 'Friar'), showed extra bands both with AFLP (seven bands in a total of 232 observed for 'Black Amber') and with ISSR (three bands in a total of 121) analysis that were not present in the parents. The number of nonparental bands was low, about $3 \%$ of the total bands scored, so incorrect parentage does not seem to be the cause. The dominant inheritance of AFLP and ISSR bands, as a heterozygous individual cannot be distinguished from a dominant homozygous, has to be considered also in the selection of backcrosses and statistical analysis routines in mapping programs. However, despite these disadvantages, the high effective multiplex ratio provided by these markers makes them very powerful tools for most of the current genome analysis. As far as we know, this is the first report on AFLP and ISSR applications in plum.

\section{Literature Cited}

Bassam, B., G. Caetano-Annoles, and P. Gresshoff. 1991. A fast and sensitive silver-staining for DNA in polyacrylamide gels. Anal. Biochem. 196:80-83.

Bellini, E., E. Giordani, V. Nencetti, and D. Paffetti. 1998. Genetic relationships in Japanese plum cultivars by molecular markers. Acta Hort. 478:5361.

Brooks, R.M. and H.P. Olmo. 1997. Register of fruit and nut varieties. 3rd ed. ASHS Press, Alexandria, Va.

Byrne, D.H. and T.G. Littleton. 1988. Electrophoretic characterization of diploid plums of the southeastern United States. J. Amer. Soc. Hort. Sci. 113:918-924.

Dirlewanger, E., S. Duha, M.A. Viruel, and R. Saunier. 1998. Identification of peach varieties using molecular markers. Acta Hort. 465:69-77.

Donini, P., M.L. Elias, S.M. Bougourd, and R.M.D. Koebner. 1997. AFLP fingerprinting reveals pattern differences between template DNA extracted from different plant organs. Genome 40:521-526.

Doyle, J.J. and J.L. Doyle. 1990. Isolation of plant DNA from fresh tissue. Focus 12:13-15.

Fang, D.Q., M.L. Roose, R.R. Krueger, and C.T. Federici. 1997. Fingerprinting trifoliate orange germplasm accessions with isozymes, RFLPs, and inter-simple sequence repeat markers. Theor. Appl. Genet. 95:211-219.

Gregor, D., W. Hartmann, and R. Stosser. 1994. Cultivar identification in
Prunus domestica using random amplified polymorphic DNA markers. Acta Hort. 359:33-40.

Halldén, C.M., M. Hansen, N.O. Nilsson, A. Hjerdin, and T. Sall. 1996. Competition as a source of errors in RAPD analysis. Theor. Appl. Genet. 93:1185-1192.

Hartl, L. and S. Seefelder. 1997. Diversity of selected hop cultivars detected by fluorescent AFLP. Theor. Appl. Genet. 96:112-116.

Howard, W.L., 1945. Luther Burbank's plant contributions. Calif. Agr. Expt. Sta. Bul. 691.

Jones, C.J., K.J. Edwards, S. Castaglione, M.O. Winfield, F. Sala, C.G. Van der Wiel, G. Bredemeijer, B. Vosman, M. Matthes, A. Daly, R. Brettschneider, P. Bettini, M. Buiatti, E. Maestri, A. Malchevschi, N. Marmiroli, R. Aert, G. Volckaert, J. Rueda, R. Linacero, A. Vazquez, and A. Karp. 1997. Reproducibility testing of RAPD, AFLP and SSR markers in plants by a network of European laboratories. Mol. Breeding 3:381-390.

Lange, D.A., S. Peñuela, R.L. Denny, J. Mudge, V.C. Concibido, J.H. Orf, and N.D. Young. 1998. A plant DNA isolation protocol suitable for polymerase chain reaction based marker-assisted breeding. Crop Sci. 38:217-220.

Lanham, P.G. and R.M. Brennan. 1999. Genetic characterisation of gooseberry (Ribes grossularia subgenus Grossularia) germplasm using RAPD, ISSR and AFLP markers. J. Hort. Sci. Biotechnol. 74:361-366.

Monte-Corvo, L., L. Cabrita, C.M. Oliveira, and J.M. Leitão. 2000. Assessment of genetic relationships among Pyrus species and cultivars using AFLP and RAPD markers. Gen. Resources Crop Evol. 47:257-265.

Nei, M. and W.H. Li. 1979. Mathematical model for studying genetic variation in terms of restriction endonucleases. Proc. Natl. Acad. Sci. USA 76:5269-5273.

Nelson, M. and M. McClelland. 1991. Site-specific methylation: Effect on DNA modification methyltransferases and restriction endonucleases. Nucleic Acids Res. 19:2045-2071.

Okie, W.R. and J.H. Weinberger, 1996. Plums, p. 559-607. In: J. Janick. and J.N. Moore (eds.). Fruit breeding, vol. I: Tree and tropical fruits. Wiley, New York.

Oliveira, C.M., M. Mota, L. Monte-Corvo, L. Goulão, and D.M. Silva. 1999. Molecular typing of Pyrus based on RAPD markers. Scientia Hort. 79:163174.

Oritz, A., R. Renaud, I. Calzada, and E. Ritter. 1997. Analysis of plum cultivars with RAPD markers. J. Hort. Sci. 72:1-9.

Powell, W., M. Morgante, C. Andre, M. Hanafrey, J.M. Vogel, S.V. Tingey, and A. Rafalski. 1996. The comparison of RFLP, RAPD, AFLP and SSR (microsatellite) markers for germplasm analysis. Mol. Breeding 2:225238.

Rafalski, J.A., J.M. Vogel, M. Morgante, W. Powell, C. Andre, and S.V. Tingey. 1996. Generating and using DNA markers in plants, p. 75-134. In: B. Birren and E. Lai (eds.). Nonmammalian genomic analysis, Academic Press, San Diego.

Rohlf, F.J. 1993. NTSYS-PC numerical taxonomy and multivariate analysis system. Exeter Publications, Setauket, N.Y.

Sambrook, J., E.F. Fritsch, and T. Maniatis. 1989. Molecular cloning: A laboratory manual. Cold Spring Habor Lab. Press, Cold Spring Harbor, N.Y.

Sensi, E., R. Vignani, W. Rohde, and S. Biricolti. 1996. Characterization of genetic biodiversity with Vitis vinifera L. Sangiovese and Colorino genotypes by AFLP and ISTR DNA marker technology. Vitis 35:183-188.

Shimada, T., H. Hayama, T. Haji, M. Yamaguchi, and M. Yoshida. 1999. Genetic diversity of plums characterized by random amplified polymorphic DNA (RAPD) analysis. Euphytica 109:143-147.

Tohme, J., D.O. Gonzalez, S. Beebe, and M.C. Duque. 1996. AFLP analysis of gene pools of wild bean core collection. Crop Sci. 36:1375-1384.

Vos, P., R. Hogers, M. Bleeker, M. Reijans, T. van de Lee, M. Hornes, A. Freijters, J. Pot, J. Peleman, M. Kuiper, and M. Zabeau. 1995. AFLP: A new technique for DNA fingerprinting. Nucleic Acids Res. 21:4407-4414.

Zietkiewicz, E., A. Rafalski, and D. Labuda. 1994. Genome fingerprinting by simple sequence repeat (SSR)-anchored polymerase chain reaction amplification. Genomics 20:176-183. 